
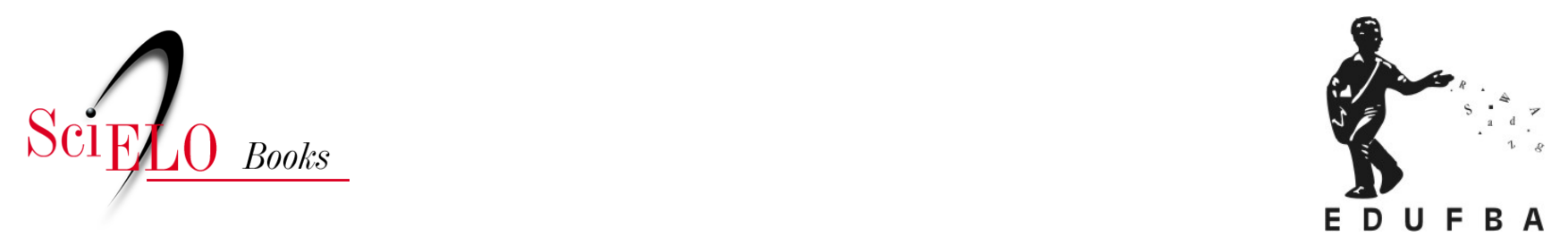

\title{
Análise de políticas de saúde bucal no Brasil estado da arte e possíveis contribuições teórico-metodológicas
}

\author{
Sônia Cristina Lima Chaves \\ Paulo Frazão \\ Sandra Garrido de Barros \\ Denise Nogueira Cruz \\ Thais Regis Aranha Rossi \\ Ana Maria Freire de L. Almeida
}

\section{SciELO Books / SciELO Livros / SciELO Libros}

CHAVES, S.C.L., FRAZÃO, P., BARROS, S.G., CRUZ, D.N., ROSSI, T.R.A., and ALMEIDA, A.M.F.L. Análise de políticas de saúde bucal no Brasil: estado da arte e possíveis contribuições teórico-metodológicas. In: TEIXEIRA, C.F., comp. Observatório de análise política em saúde: abordagens, objetos e investigações [online]. Salvador: EDUFBA, 2016, pp. 267-303. ISBN 978-85-232-2021-1. https://doi.org/10.7476/9788523220211.0009.

All the contents of this work, except where otherwise noted, is licensed under a Creative Commons Attribution 4.0 International license.

Todo o conteúdo deste trabalho, exceto quando houver ressalva, é publicado sob a licença Creative Commons Atribição 4.0. 
Sônia Cristina Lima Chaves, Paulo Frazão, Sandra Garrido de Barros, Denise Nogueira Cruz, Thais Regis Aranha Rossi e Ana Maria Freire de L. Almeida

\section{ANÁLISE DE POLÍTICAS DE SAÚDE BUCAL NO BRASIL estado da arte e possíveis contribuições teórico-metodológicas}

\section{Introdução}

Estudos de análise de políticas públicas de saúde bucal no Brasil são recentes e com incipiente produção de conhecimento, ainda que haja esforço teórico empreendido nas duas últimas décadas. Nesse sentido, este capítulo está apresentado em três tópicos. $\mathrm{O}$ primeiro busca mapear a produção científica nacional sobre as políticas de saúde bucal no Brasil, em três importantes eixos: atenção básica, atenção especializada e fluoretação das águas de abastecimento público. No segundo tópico, apresenta os principais objetivos e estudos já conduzidos e em curso do eixo temático de análise de políticas de saúde bucal do Projeto do Observatório de Análise Política em Saúde. Ao final, apresenta as principais abordagens teóricas e metodológicas que possibilitem a compreensão do processo de formulação e implementação no país, buscando orientar estudos futuros. 


\section{Estado da arte sobre a Política Nacional de Saúde Bucal segundo os eixos}

O objetivo deste tópico é fazer um breve balanço do estado da arte e das principais evidências trazidas por publicações científicas dos últimos 11 anos, que correspondem ao período de existência da política de saúde bucal brasileira.

\section{Atenção à saúde bucal na atenção primária}

A Política Nacional de Saúde Bucal (PNSB), lançada em 2004 e denominada Brasil Sorridente, aponta diretrizes para organização da atenção tendo em vista o princípio da integralidade do cuidado, assumindo, inclusive, a atenção primária à saúde como nível prioritário para estruturação da rede de serviços de saúde bucal e porta de entrada do usuário no sistema de saúde, com destaque para a Estratégia Saúde da Família (ESF). (BRASIL, 2004)

Os pressupostos e princípios norteadores da PNSB foram mantidos no período transcorrido ao seu lançamento e, também, observa-se um crescimento do número de Equipes de Saúde Bucal (ESB) implantadas no país, de modo que, em dezembro de 2004, eram 8.234 equipes modalidade I na ESF e, em setembro de 2015, esse número correspondia a 22.309, segundo dados do Ministério da Saúde. (BRASIL, 2015)

A expansão das ESB na atenção primária é um elemento que tem provocado a realização de estudos empíricos e de reflexões sobre a atenção à saúde bucal. Nesse sentido, a revisão de trabalhos publicados em formato de artigo, entre 2004 e novembro de 2015, que tinham a PNSB/2004 como descritor revela importantes contribuições, mas, também, lacunas que impõem novas investigações.

Como principais contribuições, pode-se afirmar que tal revisão revela que os estudos tratam em sua maioria da organização/modelo de atenção à saúde bucal, incluindo nessa dimensão o processo de trabalho das ESB na ESF; de estudos na perspectiva da avaliação dos 
serviços, com estudos com análise de indicadores e da produção ambulatorial. Poucos estudos refletem sobre a implementação da PNSB.

Os estudos empíricos sobre o processo de trabalho, seja na construção do cuidado em saúde bucal (AQUILANTE; ACIOLE, 2015) ou no cotidiano das ESB/ESF (PIMENTEL et al., 2010), revelam desafios na concretização das práticas dos profissionais, bem como dos pressupostos da PNSB para o primeiro nível de atenção.

A avaliação da organização da atenção primária à saúde bucal, a partir da PNSB, seja por meio da análise de documentos institucionais (DITTERICH; R.; DITTERICH, A.; BALDANI, 2015) ou a partir dos dados de produção ambulatorial e de repasses financeiros (MAIA; KORNIS, 2010) também revelam limites na atuação das ESB e aponta que a expansão da saúde bucal na atenção primária à saúde parece estar mais associada aos repasses dos recursos financeiros do que a um planejamento estratégico situacional.

A distância existente entre os resultados apresentados nas investigações e os pressupostos da PNSB também foi observada em uma análise foucaultiana da organização dos modelos de atenção à saúde bucal e as políticas de saúde no Brasil. (PIRES; BOTAZZO, 2015) Percebe-se ainda que há poucos trabalhos sobre a implementação da PNSB que tenham alguma direcionalidade para a atenção primária. (NASCIMENTO et al., 2009; SOARES et al., 2011) Neste particular, destaca-se que os limites na implementação da PNSB, no âmbito municipal, podem estar relacionados com a "baixa capacidade de governo", e também ausência de "um projeto de saúde bucal consistente”. (SOARES; PAIM, 2011, p. 972)

Por fim, é fundamental registrar que não foi observado nenhum artigo que fizesse uma análise política do Brasil Sorridente no âmbito da atenção primária.

\section{Atenção odontológica especializada}

A carta de intenção da PNSB - Brasil Sorridente, lançada em 2004, chamava atenção para a baixa capacidade de oferta dos servi- 
ços de atenção especializada, que não passavam de 3,5\% do total de procedimentos clínicos odontológicos no ano de 2003. (BRASIL, 2004) Os resultados de dois inquéritos epidemiológicos, o Relatório do Projeto SBBrasil (2003) e a Pesquisa Nacional por Amostra de Domicílio (PNAD) (2003), revelaram que a proporção de brasileiros que declarou nunca ter feito uma consulta ao dentista permaneceu muito alta (15,9\%), e maior entre os residentes das áreas rurais e entre os mais pobres. Os dados do SBBrasil mostraram também a elevada perda dental e edentulismo em adultos e idosos e permanência de diferenças regionais, sendo as regiões Norte e Nordeste com predomínio dos maiores índices de dentes perdidos em todas as PNSB, que teve a organização da atenção especializada, aqui entendida como sinônimo de atenção secundária, como um de seus principais eixos. (BRASIL, 2004) Com a implementação dos Centros de Especialidades Odontológicas (CEO), em 2004, a atenção odontológica especializada teve seu financiamento ampliado, aumentou consideravelmente o número de profissionais e municípios atendidos em relação aos governos anteriores a 2003. A criação dos Laboratórios Regionais de Próteses Dentárias (LRPD), a partir do ano de 2010, também possibilitou crescimento na oferta desse serviço de reabilitação oral.

É inegável o avanço da atenção odontológica especializada no âmbito do Sistema Único de Saúde (SUS), a partir da PNSB. Entre 2004 e 2014, foram implantados 1.030 CEOs em 854 municípios de todas as regiões do país, com maior concentração no Nordeste e Sudeste. Distribuição semelhante ocorre quanto aos LRPDs, que se encontram em maior quantidade nas regiões Nordeste e Sudeste, que apresentam o maior número de próteses dentárias entregues. (BRASIL, 2015)

Os CEOs devem se constituir como o principal serviço de referência para a atenção básica no que tange aos procedimentos odontológicos especializados. Vazquez e colaboradores (2014) destacam que a relação entre a atenção básica e os demais níveis da atenção não deve se restringir a fluxos e sim a processos (dinâmicos, democráticos 
e fundados na equidade), e ainda que para o alcance da integralidade deva haver o estabelecimento de interface entre os níveis de atenção.

Na saúde bucal, o acesso aos serviços e a continuidade do cuidado são desafios enfrentados pelos gestores. Atender a demanda por saúde bucal que emerge na atenção primária incluindo outros níveis de atenção, na perspectiva da integralidade é um problema para a maioria dos municípios. Estudo em um município paulista verificou que o CEO referencia, contrarreferencia e atende à maioria da demanda, independentemente da especialidade, porém, ainda há muita evasão durante o tratamento odontológico, o que serve de alerta para os gestores desenvolverem métodos de controle dos pacientes atendidos, com vistas à diminuição de gastos e ao aumento da resolutividade dos serviços, com a conclusão dos tratamentos iniciados. (SALIBA et al., 2013) A integralidade na prática é sempre uma construção local, com limites e possibilidades de cada equipe, dos recursos disponíveis, da atuação dos gestores ou das cobranças dos usuários. (SANCHEZ et al., 2015)

Outro fator relevante para a garantia da integralidade na assis271 tência à saúde bucal nos CEOs é a maior cobertura da atenção primária no território em que o serviço especializado se situa. (CHAVES et al., 2010; MACHADO; SILVA; FERREIRA, 2015) Chaves e colaboradores (2010) reforçam que a instalação de CEOs em cidades com atenção primária não estruturada pode levar ao atendimento da livre demanda e de procedimentos básicos nesses serviços. Há locais onde o melhor cumprimento de metas do CEO ainda se concentra no subgrupo de procedimentos de atenção básica em detrimento dos demais subgrupos. (GÓES et al., 2012; OLIVEIRA, E.; QUEIRÓZ; OLIVEIRA, R. , 2014)

Além da interface entre a atenção primária e a especializada, outra questão discutida na literatura é a acessibilidade. A acessibilidade diz respeito às características dos serviços e dos recursos de saúde que facilitam ou limitam seu uso por potenciais usuários. A acessibilidade é, assim, fator da oferta importante para explicar as variações no uso de serviços de saúde de grupos populacionais, e representa 
uma dimensão relevante nos estudos sobre a equidade nos sistemas de saúde. (TRAVASSOS e MARTINS, 2004)

Pinto e colaboradores (2014) analisaram a acessibilidade à atenção especializada numa região com 24 municípios após a implantação de um CEO regional no estado do Ceará, e verificaram que apesar de o serviço estar adequadamente preparado para atender à demanda pactuada, existem barreiras geográficas (distância e carência de transporte), financeiras (custo do transporte) e organizacionais (falta de dados epidemiológicos para pactuação e oferta de vagas à noite) que dificultam a acessibilidade e melhores taxas de aproveitamento e utilização dos serviços oferecidos nessa unidade. O simples fato de aumentar a oferta de um serviço especializado não é suficiente para que se obtenha acesso e uma maior resolutividade. (GOÉS et al., 2012; PINTO et al., 2014)

Zaitter e colaboradores (2009) apontam a falta de recursos materiais e profissionais na atenção básica como um fator gerador do aumento na demanda em algumas especialidades odontológicas, es272 pecialmente na endodontia. Os autores sugerem a realização de triagem (pré-avaliação) constante nos pacientes que aguardam em fila de espera pelo especialista, priorizando o agendamento da consulta além de favorecer a relação paciente-profissional.

Estudo em municípios baianos apontou que aqueles com menor escolaridade e expostos a uma pior organização do serviço usaram menos o CEO. Os autores verificaram também uma tendência pró equidade no atendimento público odontológico dos municípios pesquisados, o que corrobora os avanços conquistados pelo SUS no âmbito da oferta de serviços. Essa tendência pode camuflar um processo de universalização seletiva, com focalização dos serviços de atenção primária para grupos mais vulneráveis e de atenção especializada para aqueles que possivelmente têm mais capital para romper as barreiras de acesso, sejam elas organizacionais ou socioculturais. (SOARES; CHAVES; CANGUSSU, 2015)

Estudos sobre as taxas de utilização de procedimentos especializados odontológicos em cidades com CEOs apontam que sua 
implementação significou melhoria na utilização desses serviços em relação a cidades sem CEOs, todavia, o desempenho desses centros nas diversas dimensões como da qualidade técnico-científica do cuidado, do cumprimento ao princípio da integralidade, da sua equidade, ainda carecem de investigações. (CELESTE et al., 2014)

O não cumprimento das metas mínimas de produção nas três especializadas básicas (endodontia, periodontia e cirurgia oral) tem sido uma realidade apontada por diversos estudos. (GÓES et al., 2012; LINO et al., 2014) Alguns fatores são apontados como críticos: o poder que cada serviço tem de direcionar a produção desses procedimentos no sentido de atingir essas metas (LINO et al., 2014); o sistema de remuneração fixa, que pode desencorajar os profissionais a cumprirem metas mínimas de oferta de serviços; a não incorporação de novas tecnologias, a exemplo de instrumentos rotatórios para a endodontia (LINO et al., 2014); o não cumprimento de carga horária dos profissionais; a dupla inserção dos dentistas no setor público e privado (CHAVES et al., 2011) aliado ao recebimento de baixos valores remuneratórios e ausência de estabilidade laboral. (OLIVEIRA, E.; QUEIRÓZ; OLIVEIRA, R., 2014)

Machado, Silva e Ferreira (2015) apontam que o melhor desempenho dos CEOs está associado às formas de organização do processo de trabalho dos profissionais, da formação das redes regionais de atenção à saúde e às características contextuais e políticas locais como a maior cobertura da ESF, desenvolvimento humano e capacidade de governo na sua implementação.

Para a melhoria de qualidade dos CEOs, Góes e colaboradores (2012) destacam a necessidade de qualificação do processo de trabalho, com ações de educação permanente e criação de residência em atenção secundária; a avaliação de tecnologias e procedimentos próprios aos CEOs, podendo ser conduzido mediante o estabelecimento de Rede de Pesquisas Clínicas para atenção secundária e ainda, a realização de pesquisa sobre o impacto da implantação do CEO no Brasil. Esses autores evidenciam também a necessidade de revisão no marco legal para a implantação e implementação dos 
CEOs pela readequação dos critérios e normas, além de definições de novos padrões e cumprimento de metas para avaliação e monitoramento de tais serviços.

Outros trabalhos que não dizem respeito especificamente a um dos eixos apresentados poderiam ser sublinhados. (CARVALHO et al., 2009; PORTILHO; FERREIRA, 2011) Entretanto, este capítulo não teve por objetivo esgotar a literatura sobre o tema, e sim reunir algumas evidências que indicam a necessidade de produzir pesquisas que contemplem as diversas lacunas metodológicas e de conhecimento existentes sobre a evolução da política, a atenção primária, a atenção odontológica especializada, a fluoretação das águas, seja em âmbito nacional, estadual ou loco-regional. Diante do cenário político e econômico desfavorável que o país atravessa em 2015, não se espera para os próximos anos aporte financeiro significativo na política de saúde bucal, havendo inclusive possibilidade de recuo dessa institucionalidade recém constituída.

\section{Fluoretação das águas de abastecimento público}

A fluoretação das águas de abastecimento público é uma estratégia populacional de prevenção da cárie dentária que consiste no ajuste do teor de fluoreto na água de consumo humano. $\mathrm{O}$ método tem sido empregado em vários países desde 1951, quando passou a ser política oficial nos Estados Unidos da América (EUA). Pela multiplicidade de interesses associados, pela complexidade das decisões envolvidas e pelos requisitos administrativos e de gestão relacionados com sua implementação, ela é considerada uma política pública. (NARVAI; FRAZÃO, 2006)

A primeira publicação que sistematizou os conhecimentos sobre a distribuição das principais doenças bucais foi a obra $A$ epidemiologia da saúde bucal (1969), de Walter J. Pelton. (FRAZÃO, 2003) Segundo o prefácio da obra, 
A odontologia passou do empirismo para o conhecimento científico no início da década de 1930 quando dois grupos no âmbito do Serviço de Saúde Pública dos EUA produziram uma ruptura teórica pela aplicação de métodos epidemiológicos nos estudos de cárie dentária. (FRAZÃO, 2003, p. 73)

Documentos mostram que foi em Oakley (estado de Idaho EUA) que, pela primeira vez, uma comunidade se posicionou politicamente para enfrentar um problema de saúde bucal. Em 1925, a autoridade sanitária de Oakley procurou McKay para transmitir as queixas dos pais sobre os dentes das crianças e a constatação de que em comunidades vizinhas tais danos não se verificavam na dentição. A hipótese recaiu sobre a fonte de captação da água de abastecimento público. Mesmo sem dispor de conhecimentos sobre a causa exata do problema, nem poder oferecer uma maior segurança, a comunidade aprovou a mudança da fonte de captação da água e uma campanha para criação de um fundo foi liderada pela liga cívica das mulheres da cidade. Sete anos e meio depois da votação que aprovou o fundo e da instalação da nova fonte de água, a população verificou o benefício da medida quando os dentes das crianças de 6 a 7 anos de idade foram examinados por McKay. Esse evento ocorreu antes do reconhecimento do flúor como fator responsável pela ocorrência dessas alterações, e é considerado um marco na história das medidas de prevenção ampla ou coletiva. (MCKAY, 1933) De fato, a fluorose dentária endêmica, antes da cárie dentária, foi o primeiro problema de saúde bucal a ser coletivamente controlado através de medida sanitária.

Embora as observações de McKay, não tivessem ainda, do ponto de vista epidemiológico, algumas características metodológicas relevantes, e que mais tarde, seriam introduzidas nas pesquisas do Serviço de Saúde Pública dos EUA, em certo sentido, sua contribuição para demonstrar a importância da epidemiologia em saúde bucal para a qualidade da vida em sociedades humanas foi tão significativa quanto a de John Snow, cuja atitude fez cessar a epidemia de cólera em Londres, a despeito de ambos desconhecerem o agente 
etiológico do agravo, respectivamente, o Vibrio cholerae e o teor excessivo de flúor na água.

A utilização dos fluoretos como meio preventivo e terapêutico da cárie dentária iniciou-se em 1945 e 1946 nos EUA e Canadá com quatro estudos pioneiros, cujo principal objetivo foi investigar a efetividade da medida. (BURT; EKLUND, 1999) Nessas pesquisas, a concentração de fluoreto foi ajustada artificialmente nas águas de abastecimento público de algumas cidades para atingir o teor adequado, enquanto em outras, o teor de fluoreto mantido foi aquele presente naturalmente na água e considerado baixo para prevenção da cárie.

Comprovada sua eficácia e segurança, ela se expandiu paulatinamente. Entre 1960 e 2006, o número de residentes beneficiados pela medida passou de cerca de 50 para 180 milhões de habitantes nos EUA, alcançando uma taxa de $60 \%$ de cobertura. Os primeiros anos de implementação da medida despertam interesse entre os pesquisadores mesmo na segunda década do século XXI. (CARSTAIRS, 2015) Ao lado da vacinação, dos dispositivos de segurança no trânsito e nos locais de trabalho, das atividades de controle das doenças infecciosas, do reconhecimento do tabagismo como prejudicial à saúde, do consumo de alimentos mais saudáveis e seguros, e de um melhor planejamento familiar, a fluoretação da água foi considerada uma das 10 medidas de saúde pública mais importantes do século XX. (FROM..., 1999)

Para o Centro de Controle e Prevenção de Doenças (CDC) dos EUA, o poder preventivo da água fluoretada varia entre $40 \%$ a $70 \%$ em crianças, a depender da prevalência de cárie, além de reduzir a perda dentária em adultos em decorrência do método possuir grande abrangência, beneficiar todos os grupos socioeconômicos e ter excelente relação custo-benefício. (FROM..., 1999) A política pública tem sido recomendada pela Organização Mundial da Saúde (OMS) e pela International Association for Dental Research (IADR), dentre outras importantes organizações de projeção internacional, por sua efetividade, segurança e baixo custo, devendo ser implementada e mantida onde for possível. (NARVAI, 2000) No início do sé- 
culo XXI, a fluoretação para fins de prevenção da cárie beneficiava cerca de 400 milhões de pessoas em diferentes países no mundo. (FRAZÃO; PERES; CURY, 2011)

Como parte da agenda política internacional de saúde pública (WORLD HEALTH ORGANIZATION, 2007), a fluoretação da água de consumo tem sido objeto de muitos estudos e pesquisas abordando diferentes aspectos a ela relacionados.

Combinado à expansão do uso de fluoretos, observou-se importante declínio da prevalência de cárie a partir dos anos 1970 nos países industrializados. De fato, a elevação e o declínio da prevalência da cárie dentária em várias regiões do mundo, no século $\mathrm{XX}$, são atribuídos principalmente à disseminação do mercado de açúcar e à expansão do uso de fluoretos agregado à água de consumo, ao sal de cozinha ou ao creme dental. (FRAZÃO, 2012) No que pese esse declínio, a doença mantém-se como um significativo problema de saúde pública na maioria dos países desenvolvidos por ser importante causa de dor e perda dentária, levando ao absenteísmo no trabalho e na escola, e ainda afetando negativamente as atividades diárias e a estabilidade emocional dos indivíduos. (SHEIHAM, 2005)

As causas do declínio em cada país têm características específicas relacionadas às políticas que dão suporte às principais estratégias populacionais de prevenção de cárie. Conforme as características de implementação e de cobertura da fluoretação da água, o declínio pode ser mais lento e desigual. Enquanto política de saúde bucal, essa estratégia populacional de prevenção da cárie pode expressar desigualdades relacionadas à implementação de políticas públicas (PERES FERNANDES; GLAZER, 2004) e funcionar como um marcador de desigualdade sociodental. (GABARDO et al., 2008)

Em países onde a cárie dentária está declinando e existem outras possibilidades de acesso aos fluoretos, pesquisas sobre sua efetividade ressurgem com relevância. (ARMFIELD, 2010) Entre 2000 e 2015, cinco importantes revisões, sendo três delas sistemáticas, foram publicadas sobre o assunto. (AUSTRALIAN GOVERNMENT, 
2007; EUROPEAN COMMISSION, 2010; IHEOZOR-EJIOFOR et al., 2015; MCDONAGH et al, 2000; TRUMAN et al., 2002)

No que pese sua segurança e custo-efetividade, a fluoretação das águas tem suscitado debates acadêmicos sobre a violação do princípio ético da autonomia (COHEN; LOCKER, 2001; KALAMATIANOS; NARVAI, 2006); sobre a efetividade do método (KUMAR, 2008) e ainda sobre a possibilidade de ocasionar riscos para a saúde. (GAZZANO et al., 2010; PECKHAM; AWOFESO, 2014)

No Brasil, após alguns estudos em cidades brasileiras, a fluoretação das águas de abastecimento público passou a ser medida obrigatória nos locais em que existe estação de tratamento de água, desde 1974. (NARVAI, 2000) Em 2004, a fluoretação foi inscrita como parte da Política Nacional de Saúde, reafirmando-se a necessidade do desenvolvimento de ações intersetoriais para expandir a medida em todo o território, garantir sua continuidade e controle por meio de sistemas de vigilância compatíveis, cuja organização compete aos órgãos de gestão do SUS. (BRASIL, 2011)

Segundo o Ministério da Saúde, mais de 100 milhões de pessoas em todo o país são beneficiadas pela medida. (ANTUNES; NARVAI, 2010) Contudo, não se dispõe de informações fidedignas para avaliar a extensão da cobertura dessa política pública intersetorial em todo o território nacional. Os dados disponíveis resultam de processos de coleta relativamente imprecisos e não validados com o emprego de técnicas adequadas. (FRAZÃO et al., 2013)

Se considerarmos a fluoretação como uma medida eficaz e eficiente, por que ainda hoje se levantam vozes contra ela? Para compreender o debate que envolve a medida, Frazão (2006, p. 137) comenta que

É necessário examinar de modo profundo as diferentes situações, desde aquelas onde a aplicação da medida foi aceita e é mantida ainda hoje, até aquelas onde sua aplicação foi recusada ou em determinado momento interrompida. O debate não se dá acima dos conflitos de interesses e da arena onde ocorre a disputa das políticas públicas de 
saúde e saneamento. Os diferentes agentes políticos, entre os quais, autoridades governamentais, parlamentares, lideranças comunitárias e representantes de empresas e organizações não levam em consideração apenas as evidências científicas, mas também e, sobretudo, questões de ordem ética, econômica, legal e ambiental que decorrem dos diferentes valores que orientam a ação dos atores políticos.

Apesar das tentativas de privatização, a água é um bem público imprescindível para a vida humana, e cada vez mais, fator de proteção social, soberania e riqueza econômica dos países. E acrescenta:

Sendo a água processada pelas estações de tratamento, o veículo do fluoreto; aspectos relacionados à propriedade e à capacidade dos mananciais e demais fontes para sua obtenção, à cobertura da rede de abastecimento, à aceitação da população em consumi-la, e à repartição dos custos do seu tratamento e distribuição, tanto pelo Estado quanto pela sociedade, são aspectos geradores de intensas disputas e debates. (FRAZÃO, 2006, p. 137)

Para compreender tais aspectos, são necessários estudos de opinião (WHYMAN; MAHONEY; BORSTING, 2015), estudos qualitativos (FERREIRA; NARVAI, 2015) e estudos embasados nas ciências humanas e sociais que reconheçam a inserção do tema dentro de uma problemática mais geral relacionada ao acesso e à qualidade da água como um bem público que mobiliza múltiplos interesses muitas vezes inconciliáveis. (EASLEY, 2013; NARVAI; FRAZÃO, 2006) Tais estudos ainda são escassos em nosso meio e vão exigir forte colaboração entre pesquisadores de diferentes áreas, podendo contribuir para um melhor entendimento do papel das instituições políticas e econômicas e dos movimentos e grupos sociais na defesa de recursos cada vez mais escassos como a água de consumo humano. $\mathrm{O}$ conflito entre grupos rivais pela apropriação de recursos escassos é central à vida política. Os interesses que movem os atores se constituem em 
um dos lugares para onde se deve olhar quando se busca investigar por que uma política pública ocorre de uma forma e não de outra. No caso do Brasil, na qual o Estado foi historicamente central na produção de políticas públicas é importante examinar também o papel das instituições políticas e econômicas e os diferentes arranjos que vão conformar a distribuição de poder e de recursos, a fim de melhor compreender a dinâmica federativa e as regras do poder local.

\section{Principais estudos do eixo temático já conduzidos e em curso}

O eixo temático da análise de política de saúde bucal no Brasil tem buscado compreender o processo de implementação entre os anos de 2002 e 2017. Assim, há estudos que visam:

a. Caracterizar o espaço social da política de saúde bucal, identificando as instituições governamentais e não governamentais e principais agentes interessados na sua implementação no período considerado;

b. Descrever e analisar as principais propostas e tomadas de posição das instituições não governamentais com relação à implementação da PNSB no período considerado;

c. Descrever a implementação da PNSB no âmbito estadual e municipal bem como os processos sócio-históricos desse desenvolvimento;

d. Analisar os processos legislativos relacionados à saúde bucal, identificando os principais agentes envolvidos, suas disposições e tomadas de posição;

e. Caracterizar a inserção do componente da saúde bucal na rede de atenção à pessoa com deficiência e também na atenção à fissura labiopalatina, e seus antecedentes. 


\section{Abordagens teóricas mobilizadas em torno da proposta}

Para o conjunto dos estudos em curso, algumas possíveis abordagens teóricas poderão ser mobilizadas.

\section{Ciclo da política}

A teoria do ciclo da política pública (Policy Cicle) tenta explicar a interação entre intenções e ações, ao tempo em que busca desvendar a relação entre ambiente social, político e econômico de um lado e o governo de outro. (PINTO, 2003) O estudo do ciclo da política pública pode se configurar em cinco grandes fases: o reconhecimento do problema, que corresponde à fase de entrada de um conflito na agenda política; a definição de propostas de soluções, que corresponde à fase de formulação da política; a escolha de uma solução, que corresponde à fase de tomada de decisão; o momento de pôr uma solução em andamento, o que equivale à fase de implementação; e, finalmente, o monitoramento de resultados ou fase de avaliação da política. Já Knoepfel, Larrue e Varone (2007) descrevem como fases do ciclo das políticas públicas: percepção e emergência de problemas, agenda, formulação da política, implementação e avaliação.

Apesar das variações encontradas na literatura, é possível observar convergências nas abordagens. Pinto (2003) entende o ciclo político nas seguintes etapas:

a. determinação da agenda, onde a dinâmica da definição do problema é questão essencial para a compreensão da política pública;

b. formulação e legitimação da política (seleção de proposta, construção de apoio político, formalização em lei);

c. implementação de políticas (operacionalização da política em planos, programas e projetos no âmbito da burocracia pública e sua execução); 
d. avaliação de políticas (relato dos resultados alcançados com a implementação das propostas e programas de governo, avaliação dos impactos dos programas e sugestão de mudanças).

A fase de implementação de políticas corresponde à etapa em que a política formulada se transforma em planos, programas e projetos no âmbito da burocracia pública e na sua execução (PINTO, 2003), à adaptação do programa às situações concretas encontradas, bem como ao momento de colocar uma determinada solução em prática. (KNOEPFEL; LARRUE ; VARONE; 2007)

A fase de implementação como momento crucial e etapa mais crítica no ciclo da política pública que envolve uma série de sistemas ou atividades da administração pública: o sistema gerencial e decisório, os sistemas de informação, os agentes implementadores da política, os sistemas logísticos e operacionais (recursos materiais e financeiros). Essa etapa pode ser considerada enquanto um jogo, no qual a autoridade central procura induzir agentes, nesse caso, implementadores, a colocar em prática objetivos e estratégias que lhe são alheias. (VIANNA; BAPTISTA, 2008)

Segundo essas autoras, a resposta dos agentes dependerá do entrosamento entre formuladores e implementadores, da compreensão da política, do conhecimento de cada fase do processo e da quantidade de mudança envolvida com a nova política. Assim, a maior clareza e conhecimento dos implementadores facilitaria o processo em si de implementação de uma política e, por outro lado, quanto maior mudança for demandada, maiores serão os obstáculos a serem superados.

Nesse sentido, Vianna e Baptista (2008) afirmam que para uma análise de implementação é necessário responder às seguintes perguntas:

+ a formulação da política apresenta objetivos, metas e direção claros?

+ os recursos necessários para sua implementação foram considerados no momento da formulação/implementação? 
- o processo de construção da estratégia de implementação é claro? Em especial quanto à divisão de atribuições e atividades? Exige mudança organizacional?

+ os atores envolvidos estão de acordo e compreendem a política traçada?

Muitos trabalhos utilizaram esse referencial teórico-metodológico para o estudo das políticas de saúde bucal. Citam-se como exemplos os estudos de Soares e Paim (2011) que analisaram a implementação da PSNB no município de Salvador, Bahia; Rendeiro (2011) que analisou a agenda de governo e a formulação da política de saúde bucal de 2000 a 2010; Rossi e Chaves (2015) que analisaram desde a entrada na agenda até a implementação dos CEOs em dois municípios de médio porte na Bahia.

\section{O Triângulo de Governo}

A obra do economista Carlos Matus (1996) é extensa e muitas são as contribuições desse autor para a análise de políticas. Neste capítulo, será destacado seu construto teórico sobre o "Triângulo de Governo”. O conceito de Triangulo de Governo (MATUS, 1996) refere-se a três variáveis que conformam os vértices de um triângulo: o projeto de governo, a capacidade de governo e a governabilidade.

Matus (1996) aborda que o projeto de governo seria um sistema propositivo ou conjuntos de propostas de ações realizadas por um ator no intuito de alcançar sua meta. Entretanto, não são apenas as circunstâncias e interesse do ator que determinam o conteúdo propositivo de suas ações e sim sua capacidade de governo.

A capacidade de governo seria a capacidade de condução ou direção e refere-se ao acervo de técnicas, métodos, destrezas, habilidades e experiências de um ator e sua equipe de governo, para conduzir o processo social a objetivos declarados, levando em consideração a governabilidade do sistema e o conteúdo propositivo do projeto de governo. A capacidade de governo se expressa na capacidade de direção, de gerência, de administração e de controle. Através das teorias, 
técnicas e métodos de planejamento é possível alterar ou melhorar a capacidade de governo e o domínio dessas técnicas constitui-se numa das variáveis mais importantes na determinação da capacidade de governo de uma equipe.

É dito que, para aprimorar a capacidade para governar, existem dois caminhos polares: o primeiro, pelo uso paciente do tempo, o que geraria após séculos, uma maturidade institucional que prescindiria métodos formais, pois estes já estariam implícitos e seriam naturais na prática da gestão pública; o segundo consiste na economia do tempo, e prioriza os métodos formais de governo e a formação acelerada de quadros de liderança tecnopolítica, a fim de forçar uma prática que não decorre naturalmente da maturidade institucional. Na visão do autor, para os países da América Latina, a única via possível seria a segunda, pois, quanto menor é a maturidade institucional, mais necessários são os métodos e as técnicas de direção e planejamento para que, dessa forma, a prática seja forçada e a maturação dos quadros burocráticos apressada.

284 O terceiro vértice do Triângulo de Governo que, somado ao projeto de governo e à capacidade de governo, representam variáveis que se entrelaçam e condicionam-se mutuamente é a governabilidade.

A governabilidade do sistema é uma relação entre o peso das variáveis que o ator controla e não controla, no processo de governo. O autor afirma que quanto mais variáveis o ator controla, maior será sua liberdade de ação e maior será, para ele, a governabilidade do sistema. A governabilidade de um sistema expressa o poder que determinado ator tem para realizar seu projeto. É uma categoria relativa a um determinado ator, às demandas e exigências que o projeto de governo impõe a ele, e à sua capacidade de governo. (MATUS, 1996)

Referente à governabilidade o autor aponta três relativizações:

a. a primeira aborda que um sistema não oferece a mesma governabilidade a todos os diferentes atores sociais, pois cada um deles controla proporções diversas de variáveis do sistema; 
b. a segunda refere-se que a governabilidade de um sistema depende do conteúdo propositivo do projeto;

c. e a terceira relativização indica que a governabilidade de um sistema é maior se o ator tem alta capacidade de governo.

Na diferenciação entre as três variáveis é possível reconhecer sistemas de natureza diferente: o sistema propositivo de ações (projeto), o sistema social (governabilidade) e o sistema de direção e planejamento (capacidade de governo). Guimarães e colaboradores (2004) apontam que o Triângulo de Governo privilegia tanto categorias normativas (existência de projetos) e categorias administrativas (capacidade técnica) como categorias políticas (governabilidade do sistema).

Observa-se importante contribuição teórico-metodológica desse referencial nos estudos na saúde bucal. Autores utilizaram o Triângulo de Governo e o Planejamento Estratégico Situacional, do mesmo autor, para construção de uma proposta de planejamento seguindo as diretrizes da PNSB. (BITTAR et al., 2009) Já Chaves e Vieira-da-Silva (2007) trabalharam a relação entre as características de governo e a atenção à saúde bucal em dois municípios da Bahia, tendo observado influências de características do governo municipal e da gestão da saúde para a organização da atenção em saúde bucal, assim como Rossi e Chaves (2015) também verificaram na implementação dos CEOs. Conforme já citado, o estudo de Soares e Paim (2011) também analisaram a implementação da PNSB no nível municipal, através das variáveis do Triangulo de Governo.

\section{Postulado de Coerência e tipologia do poder em saúde}

Elementos conceituais e metodológicos podem ser utilizados para análises políticas a partir das contribuições sobre o planejamento em saúde e das análises sobre a realidade política latino-americana desenvolvida por Mário Testa. (TEIXEIRA, 2010) Nesta seção, terão destaque o "Postulado de Coerência" e sua elaboração sobre a tipologia de poder. 
Testa (1992), através do Postulado de Coerência, aponta que os propósitos de uma instituição, os métodos que utiliza para alcançá-los e a organização que assume devem ser coerentes. Essa relação de coerência exprime-se de duas maneiras: determinação e condicionamento. A relação entre esses elementos é descrita em forças positivas, determinantes dos limites dentre os quais devem se dar as realizações, sua lógica não é estritamente causal, e forças negativas ou condicionantes, que fixam limites para a não ocorrência delas.

O método refere-se à "teoria do problema que o método procura resolver”. No Postulado de Coerência, os propósitos determinam os métodos e esses determinam a organização, na medida em que esta última condicionará os métodos e esses poderão condicionar os propósitos.

No que tange à organização, quanto à relação de coerência, esta será determinada pelo propósito de governo e pela organização. Para Testa (1992), a organização constitui-se "uma cristalização da história”. A análise de organização em um dado momento retrata indiretamente outras determinações advindas do passado juntamente com as atuais.

A tipologia para análise do poder em saúde traz a distinção entre os poderes político, técnico e administrativo. (TESTA, 1992) Existem diversos autores que trazem conceitos e reflexões sobre o poder que podem ser bastante úteis para o estudo de políticas. Entretanto, neste tópico, será focalizada a contribuição de Mário Testa. O poder político expressa a capacidade de mobilizar grupos sociais em defesa de suas necessidades e interesses. Essas características expressam a capacidade de manipular recursos, informações e interesses que acumulam determinadas pessoas, grupos sociais e/ou instituições. Essa modalidade de poder surge como expressão da ideologia em dois eixos: saber e prática. Na dinâmica do poder, os poderes técnico e administrativo ficam subordinados ao poder político em algum momento. (TESTA, 1992)

O poder técnico consiste na capacidade do sujeito/dirigente/ técnico de gerar, aceder, lidar com a informação de características 
distintas. As informações por ele geradas podem estar em variados aspectos (médico, sanitária, administrativo e marco teórico) e operar em muitos âmbitos (docência, investigação, serviços, administração superior, população). Refere-se às instâncias e procedimentos de geração, processamento (transformação dos dados em informação) e uso da informação em relação aos grupos sociais que lidam com cada uma dessas instâncias. (TESTA, 1992)

O poder administrativo representa a capacidade do sujeito de se apropriar e distribuir recursos. O financiamento apresenta-se como sua maior expressão, sendo fundamental nos deslocamentos do poder dentro do setor, sem contudo, produzir mudanças que possam alterar a estrutura social. Essa modalidade de poder deve ser analisada referindo-se à tomada de decisões, pois o uso desse poder (decisões administrativas) implica eficácia e eficiência política, isto é, possui uma consequência sobre grupos sociais afetados pela decisão. Tal consequência pode se traduzir em aumento ou diminuição do apoio que cada grupo presta aos que tomam as decisões e a todos os demais e produzem mudanças que viabilizam outras decisões. Assim, ao se tomar uma decisão administrativa, iniciam-se dois tempos: o político, que corresponde ao tempo que a decisão leva para produzir apoio ou oposição dos grupos sociais interessados ou afetados pelo problema, e o técnico, compreendendo o tempo que leva a decisão para ser implementada até obter a eficácia operativa. (TESTA, 1992)

Foi realizada uma articulação entre o Triangulo de Governo e o Postulado da Coerência por Vilasbôas e Paim (2008) que foi adaptado por Rossi e Chaves (2015) para o estudo da implementação da atenção especializada em saúde bucal. As contribuições de Carlos Matus e Mário Testa também foram utilizadas para avaliar o planejamento estratégico de saúde bucal na ESF em um município de Santa Catarina. (BASTOS SORATTO; SÔNEGO, 2013)

\section{Processo de trabalho em saúde}

A organização das práticas pode ser estudada através da teoria do processo de trabalho em saúde proposto por Mendes-Gonçalves 
(1992). O autor estudou a aplicação da teoria marxista do trabalho ao campo da saúde. (PEDUZZI; SCHRAIBER, 2009) Na concepção de Mendes-Gonçalves (1992), trabalho é a transformação de fragmentos parciais da natureza, através de gasto de energia e com a utilização de certos recursos. O autor situa o processo de trabalho em saúde como um dos polos de uma tríplice relação dialética entre o homem e a natureza.

No estudo do processo de trabalho em saúde, Mendes-Gonçalves (1992) analisa os seguintes componentes: o objeto do trabalho, os instrumentos, a finalidade e os agentes. Destaca ainda, que esses elementos precisam ser examinados de forma articulada, pois, somente na sua relação recíproca, configura um dado processo de trabalho específico.

O objeto, em sua relação com o processo de trabalho, não se delimita por si mesmo, é delimitado por um olhar que contém um projeto. O objeto será o alvo da transformação, representado na saúde pelo que Mendes-Gonçalves (1992) chama de carecimentos, entendido como necessidades de saúde. A apreensão do objeto consiste em identificar as características que permitem a visualização do produto final, antevisto nas finalidades do trabalho. (MENDESGONÇALVES, 1994) "O objeto não se impõe em nenhum caso naturalmente, mas corresponde a um olhar enviesado que nele discrimina a potencialidade do produto." (MENDES-GONÇALVES, 1994) Outro aspecto importante a ressaltar é a noção de finalidade e do sentido teleológico do processo de trabalho humano. A finalidade é chamada de tensão da vontade.

Para apreender o objeto de trabalho, o agente opera saberes. O saber consiste em "generalizações conscientes e estruturadas a partir da prática e que expressam tanto nos instrumentos quanto nos discursos a sua materialidade sob formas diversas". (MENDESGONÇALVES, 1994) O instrumento de trabalho serve para intermediar a ação humana sobre os objetos conforme o processo social e histórico que inclui a reprodução social. Os instrumentos de trabalho representam a forma pela qual a energia se incorpora no 
processo de trabalho e devem ter capacidade de sintetizar as qualidades do objeto e o projeto de mudança numa ação transformadora. Dessa forma, o meio de trabalho é o complexo de coisas que o trabalhador insere entre si e o objeto de trabalho e lhe serve para dirigir sua atividade sobre esse objeto. (MENDES-GONÇALVES, 1992)

Ao discutir as relações que ocorrem no processo de trabalho das equipes de saúde, Mendes-Gonçalves (1994) considera que a tecnologia é um conjunto de saberes e instrumentos que expressa, nos processos de produção dos serviços, a rede de relações sociais entre agentes e práticas, conformada em uma totalidade social, que é constituída não apenas pelo saber, mas também pelos seus desdobramentos materiais e não materiais.

Há diferenciação de instrumentos materiais e não materiais. Os primeiros são os equipamentos, material de consumo, medicamentos, instalações, outros. Os segundos são os saberes, que articulam em determinados arranjos os sujeitos (agentes do processo de trabalho) e os instrumentos materiais. Estes se constituem nas ferramentas principais do trabalho de natureza intelectual. $\mathrm{O}$ autor salienta que esses saberes são também os que permitem a apreensão do objeto de trabalho. (PEDUZZI; SCHRAIBER, 2009)

O caráter de movimento e historicidade é destacado, fazendo alusão a um "retrato estático da realidade deveras dinâmica", que só tem sentido se servir de aproximação à prática, vinculada e desenvolvida ao homem prático. Assim, as práticas de saúde representam a "reiteração articulada de um modo de inserção na divisão social do trabalho relacionada à reprodução de padrões histórica e socialmente significativos de normatividade”. (MENDES-GONÇALVES, 1992 , p. 65)

$\mathrm{O}$ agente do trabalho pode ser interpretado, ele próprio, como instrumento do trabalho e, imediatamente sujeito da ação, na medida em que traz, para dentro do processo de trabalho, além do projeto prévio e sua finalidade, outros projetos de caráter coletivo e pessoal. (PEDUZZI; SCHRAIBER, 2009) 
O processo de trabalho tem sido alvo de muitos estudos em saúde bucal. Entretanto, poucos vêm utilizando a perspectiva defendida por Mendes Gonçalves. Um estudo utilizou o referencial descrito na análise da atenção secundária (ROSSI; CHAVES, 2015), entretanto os outros diversos estudos encontrados utilizam outras perspectivas para análise do processo de trabalho, muitas vezes sem mesmo referir o referencial teórico que embasou o estudo.

\section{0 uso do referencial bourdieusiano na análise de políticas de saúde bucal}

Para Bourdieu (1996), a análise sociológica é um poderoso instrumento de conhecimento de si, como ser social e singular, visto que fundamenta sua teoria na ação humana/individual. Atribui primazia às relações, opondo-se ao pensamento substancialista e do senso comum, que considera a relação entre posições sociais e gostos como mecânica e direta, como uma propriedade substancial, uma espécie de essência biológica ou cultural. Tem como conceitos fundamentais de sua teoria da ação as noções de espaço, campo, habitus ${ }^{1}$ e capital. Busca romper com noções incorporadas ao discurso acadêmico como sujeito, motivação, ator, papel, e com oposições como individual-coletivo, objetivo-subjetivo, consciente/inconsciente. (BOURDIEU, 1996)

Os agentes distribuem-se no espaço social ocupando posições de acordo com seu volume de capital global, em especial os capitais cultural e econômico, bem como os capitais político, científico, burocrático e simbólico. As diferentes posições sociais correspondem

1 Habitus é o princípio gerador e unificador que representa as características intrínsecas e relacionais de uma posição em um estilo de vida (escolhas de pessoas, bens e práticas), gerando práticas distintas e distintivas. É o senso prático do que se deve fazer em uma dada situação. Corresponde às disposições dos agentes, seus esquemas de percepção, produzidos pela história coletiva, modificados pela história individual de cada um, e incorporados de forma inconsciente. (BOURDIEU, 1996) 
a diferentes disposições ou gostos (habitus) e tomadas de posição. (BOURDIEU, 1996, 2008)

Bourdieu adota o conceito de agente para romper com as tradições que consideram as ações individuais como resultantes de processos interiores, mentais, independentes de qualquer influência externa. Assim, nem toda ação humana seria uma ação consciente, como se os agentes agissem sempre de maneira a obter o máximo de eficácia com o menor custo, pautados pelo interesse econômico. Compreende as ações individuais como resultantes dos constrangimentos objetivos do campo e das determinações subjetivas resultantes do habitus. Ou seja, a teoria da ação de Bourdieu (1996, 2008) considera que a maior parte das ações humanas tem por base algo além da intenção, e, mesmo que lúcidas, são uma construção social.

Bourdieu (1996) considera que a maioria das condutas humanas acontece em espaços de jogo, mas muito raramente estão assentadas em intenções estratégicas verdadeiras. A antecipação do jogador é imediata, dada ao conhecimento do jogo, é o senso prático: o jogador sabe onde deve estar e o que deve fazer, pois tem o sentido do jogo. É como se algo que não é imediatamente percebido já estivesse ali. Faz parte do habitus do agente do campo.

Nesse sentido, o objeto de pesquisa deve ser definido em função de uma problemática teórica que questione sistematicamente aspectos da realidade e diferentes técnicas podem contribuir para o seu conhecimento, desde que a sua utilização seja adequada ao objeto em questão e que esta seja objeto permanente de reflexão, de forma a controlar a aplicação da(s) técnica(s). (BOURDIEU; CHAMBOREDON; PASSERON, 2007)

Assim, a aplicação de diferentes técnicas pertinentes ao estudo do objeto pode ser verificada nos trabalhos empíricos de Bourdieu, como por exemplo, em A Distinção, onde se utiliza de dados secundários, de dados primários relativos a uma pesquisa através de questionários, associada ao uso de fotografias; sempre reconhecendo e tentando superar os limites da utilização de dados secundários e dos questionários; 
bem como, a utilização de estratégias de observação e entrevistas em situação real e do diário de pesquisa. (BOURDIEU, 2008)

Bourdieu (1996) aponta o estudo da gênese como importante estratégia de ruptura com o senso comum. A análise sócio-histórica contribui para identificação dos agentes e disputas envolvidos na constituição de um campo ou subespaço social, permite compreender que o que ocorreu não era a única possibilidade, evidenciando possíveis não realizados, bem como as condições históricas que possibilitaram que aquele desfecho fosse possível. (BARROS, 2013)

A análise a partir do referencial teórico bourdieusiano permite a articulação entre estruturas objetivas e mentais, internas e externas, e as trajetórias dos agentes envolvidos, buscando uma integração entre o material e o simbólico. O referencial e a epistemologia bourdieusianos foram utilizados por Patrice Pinell (2010) para a análise sociológica da gênese de quatro políticas públicas de saúde na França (política em favor da infância anormal, política de luta contra a toxicomania, política de luta contra o câncer e política de 292 luta contra a aids). Nos estudos de Pinell (2010), a política aparecia como pano de fundo de um problema sociológico objeto de estudo, de modo que o autor realizou um esforço inverso ao da maioria dos pesquisadores de ciências políticas, analisando a política a partir de um referencial teórico sociológico, mas sem uma teoria prévia a ter sua pertinência verificada pela análise dos casos. A posteriori, Pinell (2010) elaborou proposições acerca dos processos comuns à emergência das políticas por ele estudadas quanto à sua gênese e evolução.

Para a emergência de uma política pública de saúde, identificou:

a. O reconhecimento pelo poder público da necessidade de medidas específicas para o enfrentamento de um determinado problema que não tem solução satisfatória no âmbito das instituições e/ou leis existentes;

b. A responsabilização do Estado a partir da identificação de um problema já existente e da inadequação das políticas de organização e/ou das práticas institucionais existentes; 
c. A necessidade de alianças entre os diferentes grupos sociais interessados no reconhecimento de determinado problema, construindo uma definição comum do problema, apesar dos diferentes pontos de vista sobre o que é o problema ou sobre as medidas a serem tomadas;

d. A negociação para a definição de uma visão comum do problema pode levar a conflitos, a uma luta simbólica pela definição do problema e suas consequências, haja vista a concorrência aparentemente irredutível entre os grupos com interesse em construir o problema social;

e. A definição do problema constrói-se pela dinâmica de um jogo social, como produto da interpenetração das estratégias dos diferentes grupos de agentes interessados a construírem o problema como um problema social. Nesse contexto, a definição será tanto mais precisa (e restrita) quanto mais forte a concorrência entre os grupos de agentes e tanto mais imprecisa quanto os grupos interessados não são concorrentes;

f. Quando os grupos chegam a superar seus eventuais conflitos de interesse, a lógica para a elaboração de um projeto comum não é o acordo sobre uma definição precisa do problema e de suas soluções, mas de produzi-las de forma suficientemente ambíguas para não evidenciar eventuais contradições;

g. A definição do problema e das soluções construídas antes do reconhecimento do problema pelo Estado leva a remodelações quando tem início a formulação da política específica pelos poderes públicos. A definição e a implantação de uma nova política levam à necessidade de ajustamento das políticas, instituições e estruturas já existentes. Isso se deve ao fato de que:

+ A expansão ou a criação de um novo espaço social com suas questões simbólicas, institucionais, profissionais e materiais em jogo tende a modificar os equilíbrios pré-existentes no mundo social; 
- A pressão sobre os poderes públicos de apresentar a nova política como uma expressão do interesse coletivo.

Com relação à evolução das políticas, considera-se que a implantação e a evolução de uma política de saúde são produtos da dinâmica de um jogo social complexo que deve considerar:

a. As evoluções de ordem médica (epidemiologia e conhecimento médico sobre a doença, técnicas, tratamentos) e de ordem social (transformações na mobilização contra a doença);

b. Os efeitos concretos da implantação da política (novas instituições, desenvolvimento de grupos profissionais, emergência de novas estruturas associativas) e os obstáculos encontrados;

c. As mudanças de governo, sendo possível a manutenção ou a mudança da maioria política;

d. As mudanças independentes da política que afetam as instituições do campo médico (reformas hospitalares, estudos médicos) ou de outros campos implicados naquela política (educação, justiça, etc.) e mais globalmente toda a sociedade (guerras ou mudanças de costumes e nas formas de controle social). (PINELL, 2010)

O referencial bourdieusiano foi utilizado por Vieira-da-Silva e Pinell (2014) para estudar a gênese da Saúde Coletiva no Brasil. Esse referencial associado às proposições de Pinell acerca dos processos comuns à emergência das políticas na sua gênese e evolução, foram utilizados no Brasil para a análise da gênese da política de controle da aids. (BARROS, 2013) e do Programa de Alimentação do Trabalhador. (SOUZA, 2013) Alguns estudos em andamento vêm se apoiando nesse referencial também para a análise das políticas de saúde bucal, bem como alguns já publicados onde os conceitos de habitus, campo e poder simbólico também foram utilizados. (AGUIAR et al., 2014; CHAVES; VIEIRA-DA-SILVA, 2008) 


\section{Considerações finais}

Espera-se, portanto, produzir conhecimento válido e teoricamente embasado que possa subsidiar a prática técnica e política daqueles que militam na área, bem como a própria reflexão sobre as relações de poder inerentes a esses processos políticos em curso, incluindo a atual conjuntura política e econômica de 2015, com mudanças dos agentes do campo burocrático da saúde bucal, incluindo a própria coordenação nacional de saúde bucal, refletindo as relações de poder do campo político que interferem nesse espaço em particular.

\section{Referências}

ANTUNES, J. L. F.; NARVAI, P. C. Políticas de saúde bucal no Brasil e seu impacto sobre as desigualdades em saúde. Revista de Saúde Pública, São Paulo, v. 44, n. 2, p. 360-5, 2010.

AGUIAR, D.M.L. et al. Oral health technicians in Brazilian primary health care: potentials and constraints. Caderno de Saúde Pública, Rio de Janeiro, v. 30, n. 7 p. 1560-1570, 2014.

AQUILANTE, A. G.; ACIOLE, G. G. O cuidado em saúde bucal após a Política Nacional de Saúde Bucal - "Brasil Sorridente": um estudo de caso. Ciência Saúde e Coletiva, Rio de Janeiro, v. 20, n. 1, p. 239-248, 2015.

ARMFIELD, J. M. Community Effectiveness of Public Water Fluoridation in Reducing Children's Dental Disease. Public health reports, Washington, v. 125, n. 5, p. 655-664, 2010.

AUSTRALIAN GOVERNMENT. National Health and Medical Research Council. A systematic review of the efficacy and safety of fluoridation. Part A: reviewofmethodologyandresults. 2007.

BARROS, S.G. A política nacional de luta contra a aids e o espaço aids no Brasil. Salvador. 2013. 274 f. Tese (Doutorado em Saúde Pública) Instituto de Saúde Coletiva, Universidade Federal da Bahia, Salvador, 2013. 
BASTOS, P. G. S.; SORATTO, M. T.; SÔNEGO, F. G. F. Planejamento estratégico em saúde bucal. Revista Inova Saúde, Criciúma, v. 2, n. 1, p. 111-117, jul. 2013.

BITTAR, T. O. et al. O PES e a construção de uma Política Nacional de saúde Bucal no Brasil. Revista da Faculdade de Odontologia, Passo Fundo, v. 14, n. 1, p. 71-76, 2009.

BOURDIEU, P. Razões práticas: sobre a teoria da ação. Campinas: Papirus. 1996.

BOURDIEU, P. A distinção: crítica social do julgamento. São Paulo: Edusp; Porto Alegre: Zouk, 2008.

BOURDIEU, P.; CHAMBOREDON, J.-C.; PASSERON, J.-C. Ofício de sociólogo: metodologia da pesquisa na sociologia. 6. ed. Petrópolis: Vozes, 2007.

BRASIL. Coordenação Nacional de Saúde Bucal. Departamento de Atenção Básica, Secretaria de Atenção à Saúde, Ministério da Saúde. Diretrizes da Política Nacional de Saúde Bucal. Brasília, DF, 2004. BRASIL. Ministério da Saúde. Portaria n ${ }^{\circ}$ 2.914, de 12 de dezembro de 2011. Dispõe sobre os procedimentos de controle e de vigilância da qualidade da água para consumo humano e seu padrão de potabilidade. Diário Oficial da União, Brasília, DF, 14 dez 2011. Seção 1, n. 239, p. 39.

BRASIL. Ministério da Saúde. Sala de Apoio a Gestão Estratégica (SAGE). Número de equipes de saúde bucal na ESF, Centros de Especialidades Odontológicas, Laboratórios de Prótese Dentária implantados e valores transferidos fundo a fundo no Brasil. Disponível em: <http://189.28.128.178/sage/>. Acesso em: 20 out 2015.

BURT, B. A.; EKLUND, S. A. Dentistry, dental practice and the community. $5^{\text {th }}$. Philadelphia: WB Saunders, 1999.

CARSTAIRS, C. Debating Water Fluoridation before Dr. Strangelove. American Journal of Public Health, New York, v. 105, n. 8 p. 1559-69, 2015.

CARVALHO, L. A. C. et al. Procedimentos coletivos de saúde bucal: gênese, apogeu e ocaso. Saúde e Sociedade, São Paulo, v. 18, n. 3, 2009. 
FROM the centers for disease control and prevention.achievements in public health, 1900-1999: fluoridation of drinking water to prevent dental caries. Jama, Chicago, v. 48, n. 41, p. 933-940, 1999.

CELESTE, R. K et al. Análise da produção ambulatorial em municípios com e sem centros de especialidades odontológicas no Brasil em 2010. Caderno Saúde Pública, Rio de Janeiro, v. 30, n. 3, p. 511-521, 2014.

CHAVES, S. C. L et al. Política Nacional de Saúde Bucal: fatores associados à integralidade do cuidado. Revista Saúde Pública, São Paulo, v. 44, n. 6, p. 1005-1013, dez. 2010.

CHAVES, S. C. L.; VIEIRA-DA-SILVA, L. M. Oral health care and health decentralization in Brazil: two case studies in Bahia State. Caderno de Saúde Pública, Rio de Janeiro, v. 23, n. 5, p. 1119-1131, 2007.

CHAVES, S.C. L. et al. Avaliação da oferta e utilização de especialidades odontológicas em serviços públicos de atenção secundária na Bahia, Brasil.Caderno Saúde Pública, Rio de Janeiro, v. 27, n. 1, p. 143-54, 2011.

COHEN, H.; LOCKER, D. The science and ethics of water fluoridation. Canadian Dental Association, Ottawa, v. 67, n. 10, p. 578-80, 2001.

DITTERICH, R.G.; DITTERICH, A. C. R.; BALDANI, M. H. A política de saúde bucal em pauta no Conselho Municipal de Saúde no Município de Nova Friburgo - RJ. Revista de odontologia da UNESP, Marília, v. 44, n. 3, p. 143-151, 2015.

EASLEY, M.W. Dental public health practice: political science meets health science - a case study in successful technology transfer. Journal of Theory and Practice of Dental Public Health, [S.I.] v. 1, n. 1., p.15-18, 2013.

EUROPEAN COMMISSION. Scientific Committee on Health and Environmental Risks. Critical review of any new evidence on the hazard profile, health effects, and human exposure to fluoride and the fluoridating agents of drinking water. Bruxelas, 2010.

FERREIRA, R. G. L. A.; NARVAI, P. C. Fluoretação da água: significados e lei da obrigatoriedade na visão de lideranças em saúde. Revista da Associação Paulista de Cirurgiões Dentistas, São Paulo, v. 69, n. 3, p. 266-71, 2015. 
FRAZÃO, P. Debate ultrapassa fronteira da ciência. Revista da Associação Brasileira de Odontologia, São Paulo, v. 14, n. 10, p. 136-7, 2006.

FRAZÃO, P. Epidemiologia da saúde bucal. In: PEREIRA, A. C. Odontologia em saúde coletiva. Porto Alegre: Artmed, 2003. p. 64-82 .

FRAZÃO, P.; PERES, M. A.; CURY, J. Qualidade da água para consumo humano e concentração de fluoreto. Revista de Saúde Pública, São Paulo, v. 45, n. 5, p. 964-973, 2011.

FRAZÃO, P. Epidemiology of dental caries: when structure and context matter. Brazilian oral research, São Paulo, v. 26, p. 108-114, 2012. Suplemento.

FRAZÃO, P. et al. Fluoretação da água e insuficiências no sistema de informação da política de vigilância à saúde. Revista da Associação Paulista de Cirurgiões Dentistas, São Paulo, v. 67, n. 2, p. 94-100, 2013.

GABARDO, M. C. et al. Waterfluoridation as a marker for socio dental inequalities. Community dentistry and oral epidemiology, Copenhagen, $\mathrm{v}$. 36, n. 2, p. 103-107, 2008.

GAZZANO, E. et al. Fluoride effects: the two faces of janus. Current Medicinal Chemistry, Schiphol, v. 17, p. 2431-2441, 2010.

GOES, P. S. A. et al. Avaliação da atenção secundária em saúde bucal: uma investigação nos centros de especialidades do Brasil. Caderno Saúde Pública, Rio de Janeiro v. 28, p. 81-89, 2012. Suplemento.

GUIMARAES, M. C. L. et al . Avaliação da capacidade de gestão de organizações sociais: uma proposta metodológica em desenvolvimento. Caderno de Saúde Pública, Rio de Janeiro, v. 20, n. 6, p. 1642-1650, 2004.

IBGE. Pesquisa nacional por amostra de domicilios. Rio de Janeiro, 2003. IHEOZOR-EJIOFOR et al. Water fluoridation for the prevention of dental caries. The Cochrane database of systematic reviews, Oxford, n. 6, 2015 .

KALAMATIANOS, P. A.; NARVAI, P. C. Aspectos éticos do uso de produtos fluorados no Brasil: uma visão dos formuladores de políticas públicas de saúde. Ciência e Saúde Coletiva, Rio de Janeiro, v. 11, n. 1, p. 63-69, 2006. 
KNOEPFEL, P.; LARRUE, C.; VARONE, F. Public Policy Analysis. Bristol: The Policy Press, 2007.

KUMAR, J. V. Is Water fluoridation still necessary? Advances in Dental Research, Alexandria, v. 20, p. 8-12, 2008.

LINO, P. A. et al. Análise da atenção secundária em saúde bucal no estado de Minas Gerais, Brasil. Ciência Saúde Coletiva, Rio de Janeiro. v. 19, n. 9, p. 3879-3888, 2014.

MACHADO, F. C. A.; SILVA, J. V.; FERREIRA, M. A. F. Fatores relacionados ao desempenho de Centros de Especialidades Odontológicas. Ciência Saúde Coletiva, Rio de Janeiro, v. 20, n. 4, p. 1149-1163, abr. 2015.

MAIA, L.S.; KORNIS, G. E. M. A Reorganização da Atenção à Saúde Bucal frente aos incentivos federais: a experiência fluminense. Revista de atenção primária saúde - APS, Juiz de Fora, v. 13, n. 1, p. 84-95, 2010.

MATUS, C. Política, planejamento e governo. 2. ed. Brasília, DF: IPEA. 1996.

MATUS, C. Teoria do jogo social. São Paulo: FUNDAP, 2005.

MCDONAGH, M. et al. A systematic review of public water fluoridation. York: NHS Centre for Reviews and Dissemination. University of York, 2000. (Report 18).

MCKAY, F. S. Mottled Enamel: the prevention of its further production through a change of the water supply at Oakley, IDA. Journal of the American Dental Association- JADA, Chicago, v. 20, n.7, p.1137-49, 1933.

MENDES-GONÇALVES, R. B. Práticas de Saúde: processos de trabalho e necessidades. São Paulo: CEFOR, 1992.

MENDES- GONÇALVES, R. B. Tecnologia e organização social das práticas de saúde: características tecnológicas de processo de trabalho na rede estadual de centros de saúde de São Paulo. São Paulo: Hucitec: Abrasco, 1994.

NASCIMENTO, A. C. et al. Oral health in the family health strategy: a change of practices or semantics diversionismo. Revista de Saúde Pública, São Paulo, v. 43, n. 3, p. 455-462, 2009. 
NARVAI, P. C.; FRAZÃO, P. Epidemiologia, política e saúde bucal coletiva. In: ANTUNES; J. L. F.; PERES, M. A. (Ed.). Epidemiologia da saúde bucal. Rio de Janeiro: Guanabara Koogan; 2006. p. 346-362.

NARVAI, P. C. Cárie dentária e flúor: uma relação do século XX. Ciência e Saúde Coletiva, Rio de Janeiro, v. 5, n. 2, p. 381-92, 2000.

OLIVEIRA, E. R. S. B.; QUEIRÓZ, D. M.; OLIVEIRA, R. F. Avaliação da atenção odontológica no município de Montes Claros (MG) utilizando o Sistema de Informações Ambulatoriais do Sistema Único de Saúde. Unimontes Científica, Montes Claros, v. 16, n.1, p. 4-14, jan./jun. 2014.

PECKHAM, S.; AWOFESO, N. Water fluoridation: a critical review of the physiological effects of ingested fluoride as a public health intervention. The Scientific World Journal, [S.I.] v. 2014, p. 1-10, 2014.

PEDUZZI, M.; SCHRAIBER, L. B. Processo de trabalho em saúde: dicionário da educação profissional em saúde. Rio de Janeiro: Fundação Oswaldo Cruz, 2009.

PERES, M. A.; FERNANDES, S. L.; GLAZER, P. K. Inequality of water fluoridation in Southern Brazil :the inverse equity hypothesis revisited. Social Science \& Medicine, New York, v. 58, n .6, p.1181-1189, 2004.

PIMENTEL, F.C. et al. Análise da atenção à saúde bucal na estratégia de saúde da família do distrito sanitário VI, Recife (PE). Ciência e Saúde Coletiva, Rio de Janeiro, v.15, n.4, p. 2189-2196, 2010.

PINELL, P. Análise sociológica das políticas de saúde. Rio de Janeiro: Ed. Fiocruz, 2010.

PINTO, I. C. M. Ascensão e Queda de uma questão na agenda governamental: o caso das organizações sociais da saúde na Bahia. Salvador, 2003. 238f. Tese (Doutorado em administração) - Faculdade de administração, Universidade Federal da Bahia, Salvador, 2003.

PINTO, V. P. T. et al. Avaliação da acessibilidade ao Centro de Especialidades Odontológicas de abrangência macrorregional de Sobral, Ceará, Brasil.Ciência e Saúde Coletiva, Rio de Janeiro, v. 19, n. 7, p. 2235$2244,2014$. 
PIRES, F. S.; BOTAZZO, C. Organização tecnológica do trabalho em saúde bucal no SUS: uma arqueologia da política nacional de saúde bucal. Saúde e Sociedade, São Paulo, v. 24, n. 1, p. 273-284, 2015.

PORTILHO, J. A. C.; FERREIRA, L. B. Sobre os avanços da Política Nacional de Saúde Bucal. Tempus: actas de saúde coletiva, Brasília, DF, v. 5, n. 3, p. 35-47, 2011.

RENDEIRO, M. M. P. O ciclo da política de saúde bucal no sistema de saúde brasileiro: atores, ideias e instituições. Rio de Janeiro, 2011. $188 \mathrm{f}$. Tese (Doutorado em Saúde pública) - Escola Nacional de Saúde Pública Sergio Arouca, Fundação Oswaldo Cruz, 2011.

ROSSI, T. R. A.; CHAVES, S. C. L. Implementação da atenção especializada em saúde bucal em dois municípios na Bahia/ Brasil. Saúde em Debate Rio de Janeiro, v. 39, p. 196-206, dez. 2015. Edição especial.

SALIBA, N. A. et al. Organização da demanda de um Centro de Especialidades Odontológicas. Revista de Odontologia da UNESP, Marília, v. 42, n. 5, p. 317-323, 2013.

SANCHEZ, H. F. et al. Integrality in everyday dental care: review of the literature. Trabalho, Educação e Saúde, Rio de Janeiro, v. 13, n. 1, p. 201-214, 2015.

SHEIHAM, A. Oral health, general health and quality of life. Bull World Health Org, Genebra, v. 83, n. 9, p. 644, 2005.

SOARES, C. L. M.; PAIM, J. S. Aspectos críticos para a implementação da política de saúde bucal no Município de Salvador, Bahia, Brasil.

Caderno de Saúde Pública, Rio de Janeiro, v. 27, n. 5, p. 966-974, maio 2011.

SOARES, F. F. et al. Atuação da equipe de saúde bucal na estratégia saúde da família: análise dos estudos publicados no período 2001-2008. Ciência e Saúde Coletiva, Rio de Janeiro, v. 16, n. 7, p. 3169-3180, 2011.

SOARES, F. F.; CHAVES, S. C. L.; CANGUSSU, M. C. T. Governo local e serviços odontológicos: análise da desigualdade na utilização local. Caderno de Saúde Pública, Rio de Janeiro, v. 31, n. 3, p. 586-596, 2015. 
SOUZA, J. C. A gênese do programa de incentivo fiscal à alimentação do trabalhador (PIFAT /PAT). 2013. 261 f. Tese (Doutorado em Saúde Pública) - Instituto de Saúde Coletiva, Universidade Federal da Bahia, Salvador, 2013.

TEIXEIRA, C. F. Enfoques teórico-metodológicos do planejamento em saúde. In: TEIXEIRA, C. Planejamento em saúde: conceitos, métodos e experiências. Salvador: EDUFBA, 2010.

TESTA, M. Pensar em Saúde. Porto Alegre: Artes Médicas, 1992.

TRAVASSOS, C.; MARTINS, M. Uma revisão sobre os conceitos de acesso e utilização de serviços de saúde. Caderno de Saúde Pública, Rio de Janeiro, v. 20, p. 190-8, 2004.

TRUMAN, B. I. et al. Reviews of evidence on interventions to prevent dental caries, oral and pharyngeal cancers, and sports-related craniofacial injuries. American Journal of Preventive Medicine, Washington, v. 23, n.1, p. 21-54, 2002.

VAZQUEZ, F. L. et al. Referencia e Contrarreferencia na atencao Secundaria em odontologia em Campinas, SP, Brasil. Ciência e Saúde Coletiva, Rio de Janeiro, v. 19, n. 1, p. 245-256, 2014.

VIANA, A. L. D. V; BAPTISTA, T. W. F. Análise de Políticas de Saúde. In: GIOVANELLA, L. et al. Políticas e sistemas de saúde no Brasil. Rio de Janeiro: Ed.Fiocruz, 2008. p. 65-106.

VIEIRA-DA-SILVA, L; PINELL, P. The Genesis of Collective Health in Brazil. Sociology of Health \& Illness, Oxford, v. 36, n. 3, p. 432-446, 2014.

VILASBÔAS, A. L. Q.; PAIM, J. S. Práticas de planejamento e implementação de políticas no âmbito municipal.Cadernos de Saúde Pública, Rio de Janeiro, v. 24, p. 1239-1250, 2008.

WORLD HEALTH ORGANIZATION- WHO. Sixtieth World Health Assembly.Resolution. Geneva, 2007.

WHYMAN, R. A.; MAHONEY, E. K.; BORSTING, T. Community water fluoridation: attitudes and opinions from the New Zealand Oral Health Survey. Australian and New Zealand journal of public health. Canberra, v. 401, n. 2, p. 186-192, 2015. 
ZAITTER W. M. et al. Avaliação da acessibilidade do paciente à clínica de especialidades de Endodontia em dois distritos de saúde do município de Curitiba (PR). Revista Sul-brasileira de Odontologia, Joinville , v. 6, n. 4, p. 413-420, 2009. 